\title{
Silencing the Expression of Cyclin G1 Enhances the Radiosensitivity of Hepatocellular Carcinoma in vitro and in vivo by Inducing Apoptosis
}

Gang Xu ( $\nabla$ zlyyxugang4124@zzu.edu.cn )

Affiliated cancer hospital of zhengzhou University

Shanshan Bu

Affiliated cancer hospital of zhengzhou university

Xiushen Wang

Affiliated cancer hospital of zhengzhou university

Hong Ge

Affiliated cancer hospital of zhengzhou university

\section{Research}

Keywords: Cyclin G1, Hepatocellular carcinoma, Radiosensitivity, Apoptosis

Posted Date: July 6th, 2020

DOI: https://doi.org/10.21203/rs.3.rs-40051/v1

License: (c) (i) This work is licensed under a Creative Commons Attribution 4.0 International License.

Read Full License 


\section{Abstract}

Background: Radiotherapy plays an important role in the treatment of hepatocellular carcinoma (HCC). Cyclin G1 was a novel member of the cyclin family, and it is abnormally expressed in HCC. The aim of this study was to investigate the role of cyclin G1 in the radiotherapy of HCC cells.

Methods: The expression of cyclin G1 was silenced by transfection of cyclin G1-siRNA into HepG2 cells, and the expression of cyclin G1 mRNA and protein was measured by qRT-PCR and western blot analysis. The proliferation was analysed by MTT assay, and the radiosensitivity of HCC cells was detected by using a colony formation assay and a xenograft tumour model. The expression of apoptosis-related proteins (Bcl-2 and Bax) was detected by western blot analysis.

Results: The expression of cyclin G1 mRNA and protein in HepG2-cyclin G1-siRNA cells is significantly decreased compared with that in HepG2 cells. Silencing the expression of cyclin G1 inhibits the proliferation of HCC cells and enhances the radiosensitivity of HepG2 cells in vitro and in vivo. HepG2cyclin G1-siRNA significantly decreases Bcl-2 expression and increases Bax expression in cells.

Conclusion: Silencing the expression of cyclin $\mathrm{G} 1$ enhances the radiosensitivity of HCC cells in vitro and in vivo, and the mechanism is probably related to the regulation of apoptosis-related proteins.

\section{Background}

Hepatocellular carcinoma (HCC) is the fifth most common cancer in men and the seventh most common in women. Patients with HCC mostly receive palliative treatments because few patients have the opportunity for curative resection [1]. Radiotherapy, such as 3-dimensional conformal radiotherapy (3DCRT), intensity modulated radiotherapy (IMRT), image-guided radiotherapy (IGRT) or stereotactic body radiation therapy (SBRT), plays an important role in the treatment of HCC [2-4]; however, there are also many adverse effects in the practice of radiotherapy [5]. The failure of radiotherapy is always caused by the risk of radiation-induced hepatic toxicity [6, 7]. HCC is usually accompanied by cirrhosis of the liver with poor hepatic function, which makes it difficult to treat with high-dose radiotherapy [8]. Low-dose radiotherapy always requires that cancer cells be very sensitive to radiotherapy to achieve curative effects. Currently, the precise mechanism modulating the radiosensitivity of HCC cells remains poorly understood [9].

Cyclin G1 was originally identified as a novel member of the cyclin family [10]. Many studies have shown that cyclin $\mathrm{G} 1$ is abnormally expressed in many malignant cancers, such as HCC [11], cervical carcinoma [12] and lung carcinoma [13], and also contributes to the recurrence and chemoresistance of hepatoma cells [11]. Targeting cyclin $\mathrm{G} 1$ exerts anticancer effects in many cancers [14-16]. Kimura et al reported that cyclin $\mathrm{G} 1$ is involved in cell cycle arrest (G2/M block) induced by radiation and that radiosensitivity is significantly enhanced in cyclin G1 gene-deleted mice and embryonic fibroblasts [17]. Cyclin $\mathrm{G} 1$ is also one of the target genes of the transcription factor p53 $[18,19]$. The p53 tumour suppressor gene is involved in the tumorigenesis, development and progression of many cancers and is closely related to the 
radiosensitivity of cancer cells $[20,21]$. Therefore, we hypothesize that cyclin $\mathrm{G} 1$ is related to the radiosensitivity of HCC cells.

In our present study, we investigated the role of cyclin $\mathrm{G} 1$ in the radiosensitivity of HCC cells. We detected the expression of cyclin $\mathrm{G} 1$ in cancer tissue and adjacent non-cancerous tissue and then evaluated the effects of silencing the expression of cyclin $\mathrm{G} 1$ on the proliferation and radiosensitivity of HCC cells. According to the results of our study, silencing the expression of cyclin $\mathrm{G} 1$ promotes proliferation and enhances the radiosensitivity of HCC cells.

\section{Methods}

\section{Cell culture and siRNA transfection}

HepG2 cells were obtained from the School of Medical Sciences, Zhengzhou University, and cultured in Roswell Park Memorial Institute (RPMI) 1640 medium (HyClone, Logan, UT, USA) with $10 \%$ foetal bovine serum (FBS) (HyClone), $100 \mu \mathrm{g} / \mathrm{ml}$ penicillin, and $0.25 \mu \mathrm{g} / \mathrm{ml}$ streptomycin at $37^{\circ} \mathrm{C}$ and $5 \% \mathrm{CO}_{2}$.

siRNA targeting the cyclin G1 gene and the negative control siRNA were synthesized by Shanghai GenePharma Co., Ltd. (Shanghai, China), and the cyclin G1 siRNA sequence was as follows:

sense: 5'-GCAAGAGCUUGUAUCCAAAUGUUTA-3',

anti-sense: 5'-UAAACAUUUGGAUACAAGCUCUUGCCA - 3'[22]. The negative control siRNA sequence was as follows:

sense: 5'-CUUCCUCUCUUUCUCUCC CUUGUGA-3',

antisense: 5'-UCACAAGGGAGAGAAAGAGAGGAAGGA-3'. According to the manufacturer's protocol, the siRNA sequences were transfected with the Lipofectamine 2000 transfection reagent.

\section{QRT-PCR analysis}

Total RNA was extracted using TRIzol (GenePharma, Co., Ltd., Shanghai, China) and reverse transcribed to cDNA. qPCR was performed in a 7300 Sequence Detection System (Applied Biosystems, Foster City, USA) using a SYBR ${ }^{\circledR}$ Green PCR kit (QIAGEN, Hilden, Germany). The primers were purchased from Shanghai GenePharma Co., Ltd. as follows: cyclin G1: forward 5'-AGCTGCAGTCTCTGTCAAG-3',

reverse 5'-ATGTCTCTGTGTCAAAGCCA - 3'; and $\beta$-actin: forward 5'-GAAATCGTGCGT GACATTA-3', reverse 5'-ACTCATCGTACTCCTGCTTG-3'. The relative expression level of cyclin $\mathrm{G} 1$ was calculated using comparative cycle threshold (Ct) methods, and $\beta$-actin was used as an internal control. The value of cells transfected with negative control siRNA was set to $100 \%$ in each run. 


\section{Cell proliferation assay}

Cells were seeded into 96 -well plates at $1.5 \times 10^{3}$ cells and $2 \times 10^{3}$ cells per well and incubated overnight. The cells were cultured for 5 days at $37^{\circ} \mathrm{C}$. 3-(4,5-Dimethylthiazol -2-yl)-2,5-diphenyltetrazolium bromide (MTT) assays were carried out at different time points: $24 \mathrm{~h}, 48 \mathrm{~h}, 72 \mathrm{~h}, 96 \mathrm{~h}$ and $120 \mathrm{~h}$. Then, $20 \mu \mathrm{l}$ MTT solution $(5 \mathrm{mg} / \mathrm{ml})$ was added to each well and incubated for an additional $4 \mathrm{~h}$ at $37^{\circ} \mathrm{C}$. Then, the MTT solution was aspirated, and $100 \mu \mathrm{l}$ DMSO was added to dissolve the formazan crystals. The number of cells was counted using a microplate reader at a wavelength of $490 \mathrm{~nm}$.

\section{Colony formation assays}

Cells were digested, and single-cell suspensions were prepared; then, cells were plated in 6-well plates at appropriate dilutions (200, 200, 400, 400, and 800 cells/well for the $0 \mathrm{~Gy}, 2 \mathrm{~Gy}, 4 \mathrm{~Gy}, 6$ Gy and 8 Gy groups, respectively) and allowed to attach overnight. The cells were irradiated with different dosages using an ONCOR linear accelerator (Siemens, MUC, Germany) at a dose rate of $300 \mathrm{cGy} / \mathrm{min}$, cultured for another 14 days, fixed with methanol, and stained with $0.05 \%$ crystal violet (Sigma-Aldrich Chemical Company, St Louis MO, USA). The number of colonies consisting of 50 or more cells was counted, and the surviving fraction was calculated. The dose-survival curves were plotted with a single-hit multitarget model using GraphPad 5 (GraphPad Software Inc., San Diego, CA, USA), and the values of $D_{0}, D_{q}$ and $\mathrm{SER}_{\mathrm{Dq}}$ were calculated.

\section{Xenograft transplantation and irradiation}

To develop xenograft tumours, HepG2 cells, HepG2-cyclin G1-siRNA negative control cells and Hep-cyclin G1-siRNA cells $\left(1.0 \times 10^{5}\right.$ cells) were subcutaneously implanted into BALB/c nude mice $(n=5)$. When xenograft tumours grew to a mean volume of approximately $50 \mathrm{~mm}^{3}$, tumours were treated with $20 \mathrm{~Gy}$ radiation in 5 fractions ( 4 Gy per fraction, once every 2 days). Each animal was earmarked and followed individually throughout the experiment. Tumour volume $\left(\mathrm{mm}^{3}\right)$ was calculated using the following formula: $\mathrm{V}\left(\mathrm{mm}^{3}\right)=$ length $(\mathrm{mm}) \times$ width $(\mathrm{mm})^{2} / 2$. The body weights of the mice were also recorded every 2 days during the experiment. All tumours were observed for 21 days, and then the mice were sacrificed, and the weights of the tumours were weighted.

\section{Western blot analysis}

Membrane protein was extracted $48 \mathrm{~h}$ after irradiation, subjected to sodium dodecyl sulfatepolyacrylamide gel electrophoresis (SDS-Page) and blotted onto a polyvinylidene difluoride membrane (Bio-Rad, CA, USA). The membranes were blocked with $5 \%$ milk for $2 \mathrm{~h}$ and incubated overnight with antibodies specific to cyclin G1 (1:1000), Bcl-2 and Bax (Cell Signaling Technology, MA, USA) (1:1000) or 
GAPDH (Abcam, MA, UK) (1:5000) at $4{ }^{\circ} \mathrm{C}$. Proteins were visualized by using the electro-chemiluminescene(ECL) procedure (Bio-Rad, CA, USA). The results were analysed using Quantity One software (Bio-Rad, CA, USA).

\section{Statistical analysis}

Data are expressed as the mean \pm standard deviation (SD) and were analysed using the Statistical Program for Social Sciences (SPSS) 10.0 software (IBM, Armonk, NY, USA). Differences between groups were determined using analysis of variance (ANOVA) or Student's t-test. A p-value less than 0.05 was considered statistically significant.

\section{Result}

\section{Silencing the expression of cyclin G1 inhibits HCC cell proliferation}

The expression of cyclin G1 mRNA in HepG2 cells was analysed by q-PCR, and as shown in Fig. 1A, the expression of cyclin G1 mRNA in HepG2-cyclin G1-siRNA cells was significantly lower than that in HepG2 cells and HepG2 cyclin G1-siRNA negative control cells. Meanwhile, there was no significant difference between HepG2 cells and HepG2 cyclin G1-siRNA negative control cells. Cyclin G1 protein expression also decreased after transduction with cyclin G1-siRNA, which was confirmed by western blot analysis (Fig. 1B). The MTT assay showed that cyclin G1-siRNA significantly inhibited the proliferation of HepG2 cells (Fig. 1C).

\section{Silencing the expression of cyclin $\mathrm{G} 1$ enhances the radiosensitivity of HepG2 cells in vitro}

Colony formation assays showed that irradiation caused a dose-dependent cytotoxic effect on HepG2 cells. Transduction with cyclin G1-siRNA sensitized HepG2 cells and successfully enhanced the effects of radiation (Fig. 2). The radiosensitization effects of cyclin G1-siRNA in HepG2 cells are summarized in Table 1.

Table 1

The radiosensitising effect of cyclin $\mathrm{G} 1$ in HepG2 cells

\begin{tabular}{|lcccc|}
\hline Groups & $\mathbf{D}_{0}(\mathrm{~Gy})$ & $\mathbf{D}_{\mathrm{q}}(\mathrm{Gy})$ & $\mathrm{SF}_{2}$ & SER $_{\mathbf{D q}}$ \\
\hline HepG2 & $1.31 \pm 0.15$ & $2.08 \pm 0.07$ & $0.70 \pm 0.05$ & \\
\hline HepG2-cyclin G1-siRNA & $0.64 \pm 0.07$ & $1.42 \pm 0.20$ & $0.36 \pm 0.04$ & $1.49 \pm 0.23$ \\
\hline HepG2-cyclin G1-siRNA negative control & $1.29 \pm 0.09$ & $2.12 \pm 0.11$ & $0.68 \pm 0.04$ & $0.98 \pm 0.07$ \\
\hline $\begin{array}{l}D_{0} \text { : lethal dose (Gy), } D_{q} \text { : quasi-threshold dose (Gy), } S F_{2} \text { : survival fraction values at 2 Gy, SER: } \\
\text { sensitisation enhancement ratio. }\end{array}$ & & & & \\
\hline
\end{tabular}

Silencing the expression of cyclin G1 enhances the radiosensitivity of HCC in vivo. 
To detect the effect of cyclin G1 on the radiosensitivity of HepG2 tumour xenografts in vivo, a xenograft analysis was performed. The data showed that silencing the expression of cyclin G1 in HepG2 cells inhibited the growth of tumour xenografts compared with the control group. After radiation, the tumour volume of tumour xenografts was significantly inhibited in the HepG2-cyclin G1-siRNA group compared with the HepG2 group, HepG2-cyclin G1-siRNA negative control group and HepG2 + irradiation group (Fig. 3A, 3B). There was no significant difference in the body weight of the mice (Fig. 3C). The change in tumour weight illustrated an inhibitory effect similar to that seen with the change in tumour volume (Fig. 4D).

\section{Silencing the expression of cyclin $\mathrm{G} 1$ decreases the expression of $\mathrm{Bcl}-2$ and increases the expression of Bax.}

$\mathrm{Bcl}-2$ and Bax proteins were detected by western blotting. As shown in Fig. 4, the expression of Bcl-2 decreased and the expression of Bax increased significantly in the HepG2-cyclin-siRNA group compared to the control group, and the change in the HepG2-cyclin G1-siRNA combined with X-ray radiation group was the most obvious.

\section{Discussion}

Radiotherapy can lead to local control in HCC patients, and the dose of radiotherapy is always limited by radiation-induced toxicity to the liver and adjacent luminal gastrointestinal organs. The application of radiosensitizers may increase the therapeutic ratio of radiotherapy. The radiosensitizers used in HCC include ferritin, conventional cytotoxic agents, halogenated pyrimidines and molecular agents (sorafenib and sunitinib). Cyclin $\mathrm{G} 1$ is an oncogene in $\mathrm{HCC}$ and plays an important role in the carcinogenesis and development of HCC. In our present study, we found that silencing the expression of cyclin G1 with siRNA enhanced the radiosensitivity of HCC cells in vitro and in vivo. More recently, Xu et al reported that silencing heat shock protein 27 increased the radiosensitivity of non-small-cell lung carcinoma cells by downregulating cyclin $\mathrm{G} 1$ [23], so targeting cyclin $\mathrm{G} 1$ enhanced radiosensitivity, which is consistent with our results.

Cyclin G1 plays an important role in the proliferation of many cancers, such as osteogenic sarcoma [15], ovarian cancer[16], breast cancer[24], pancreatic ductal adenocarcinoma[35] and papillary thyroid carcinoma[26]. In our study, we found that silencing the expression of cyclin G1 inhibited the proliferation of HepG2 cells and xenograft tumour growth in vivo. According to the literature reports, the effect of cyclin $\mathrm{G} 1$ on proliferation is probably related to p53 or MDM2[27]. In cyclin G1-deficient tissue, p53 levels increase, and the loss of cyclin $\mathrm{G} 1$ protects against N-diethylnitrosamine (DEN)-induced hepatocarcinogenesis [28].

Numerous studies have shown that the radiosensitivity of tumour cells is associated with apoptosis [29] and that induction of apoptosis can enhance the radiosensitivity of cancer cells. Loss of cyclin $\mathrm{G} 1$ can induce apoptosis in uterine leiomyoma cells [30]. We also found that X-ray irradiation and silencing the expression of cyclin $\mathrm{G} 1$ can inhibit the expression of Bcl-2 and promote the expression of Bax. These results indicate that X-ray irradiation and cyclin $\mathrm{G} 1$ can induce apoptosis. 


\section{Conclusions}

Silencing the expression of cyclin G1 can enhance the radiosensitivity of HepG2 cells. The mechanism may be related to the regulation of apoptosis-related proteins. This study provides a new possible pathway to increase the radiosensitivity of HCC cells.

\section{List Of Abbreviations}

HCC: hepatocellular carcinoma; 3-DCRT: 3-dimensional conformal radiotherapy; IMRT: intensity modulated radiotherapy; IGRT: image-guided radiotherapy; SBRT: stereotactic body radiation therapy; RPMI: Roswell Park Memorial Institute; MTT: 3- (4,5-Dimethylthiazol -2-yl)-2,5-diphenyltetrazolium bromide; D0: lethal dose (Gy), Dq: quasi-threshold dose (Gy), SF2: survival fraction values at 2 Gy, SER: sensitisation enhancement ratio; SDS-Page: sodium dodecyl sulfate-polyacrylamide gel electrophoresis; SPSS: Statistical Program for Social Sciences; ANOVA: analysis of variance.

\section{Declarations}

\section{Ethics approval and consent to participate}

The experimental protocol was established, and was approved by the Ethics Committee of the Affiliated Cancer Hospital of Zhengzhou University.

\section{Consent for publication}

Not applicable.

\section{Availability of data and materials}

All data generated or analysed during this study are included in this published article.

\section{Competing interests}

The authors declare no conflicts of interest.

\section{Funding}

This work was Funded by Science and Technology Department of Henan Province (CN) (No.192102310102).

\section{Author's contributions}

GX designed the study; GX, SSB and XSW performed the experiments囚acquired and analyzed data; HG interpreted the data; $\mathrm{GX}$ and $\mathrm{HG}$ wrote the manuscript; all authors read and approved the final version of the article. 
Acknowledgements:

Not applicable.

\section{References}

1. Forner A, Reig M, Bruix J. Hepatocellular carcinoma. Lancet. 2018; 391(10127): 1301-1314. doi: 10.1016/S0140-6736(18)30010-2.

2. Park S, Yoon WS, Rim CH. Indications of external radiotherapy for hepatocellular carcinoma from updated clinical guidelines: Diverse global viewpoints. World J Gastroenterol. 2020;26(4):393-403. doi: 10.3748/wjg.v26.i4.393.

3. Choi SH, Seong J. Strategic application of radiotherapy for hepatocellular carcinoma. Clin Mol Hepatol. 2018; 24(2): 114-134. doi: 10.3350/cmh.2017.0073.

4. Huo YR, Eslick GD. Transcatheter arterial chemoembolization plus radiotherapy compared with chemoembolization alone for hepatocellular carcinoma: a systematic review and meta-analysis. JAMA Oncol. 2015; 1(6): 756-765. doi: 10.1001/jamaoncol.2015.2189.

5. Song JH, Jeong BK, Choi HS, Jeong H, Lee YH, Kim HJ, et al. Defining Radiation-Induced Hepatic Toxicity in Hepatocellular Carcinoma Patients Treated with Stereotactic Body Radiotherapy. J Cancer. 2017;8(19):4155-4161. doi:10.7150/jca.21561.

6. Song JH, Son SH, Kay CS, Jang HS. Identification of biologically effective dose-volumetric parameters that predict radiation-induced hepatic toxicity in patients treated with helical tomotherapy for unresectable locally advanced hepatocellular carcinoma. Medicine (Baltimore). 94 (43), e1904.

7. Huang P, Yu G, Kapp DS, Bian XF, Ma CS, Li HS, et al. Cumulative dose of radiation therapy of hepatocellular carcinoma patients and its deterministic relation to radiation-induced liver disease. Med Dosim. 2018;43(3):258-266. doi:10.1016/j.meddos.2017.10.002

8. Schlachterman A, Craft WW Jr, Hilgenfeldt E, Mitra A, Cabrera R. Current and future treatments for hepatocellular carcinoma. World J Gastroenterol. 2015; 21(28):8478-8491.

9. Lee IJ, Seong J. Radiosensitizers in hepatocellular carcinoma. Semin Radiat Oncol. 2011;21(4):303311. doi:10.1016/j.semradonc.2011.05.008

10. Tamura K, Kanaoka Y, Jinno S, Nagata A, Ogiso Y, Shimizu K, et al. Cyclin G: a new mammalian cyclin with homology to fission yeast Cig1. Oncogene. 1993; 8(8): 2113-2118.

11. Wen W, Han T, Chen C, Huang L, Sun W, Wang X, et al. Cyclin G1 expands liver tumor-initiating cells by Sox2 induction via Akt/mTOR signaling. Mol Cancer Ther. 2013; 12(9): 1796-1804.

12. Liang J, Bian ML, Chen QY, Liu X, Ou H, Li M, et al. Relationship between cyclin G1 and human papilloma virus infection in cervical intraepithelial neoplasia and cervical carcinoma. Chin Med Sci J. 2006; 21(2):81-85. 
13. Zhao X, Liu M and Li D. Oleanolic acid suppresses the proliferation of lung carcinoma cells by miR122/Cyclin G1/MEF2D axis. Mol Cell Biochem. 2015; 400(1-2):1-7.

14. Chawla SP, Bruckner H, Morse MA, Assudani N, Hall FL, Gordon EM, et al. A Phase I-Il Study Using Rexin-G Tumor-Targeted Retrovector Encoding a Dominant-Negative Cyclin G1 Inhibitor for Advanced Pancreatic Cancer. Mol Ther Oncolytics. 2018;12:56-67. doi:10.1016/j.omto.2018.12.005

15. Skotzko M, Wu L, Anderson WF, Gordon EM, Hall FL. Retroviral vector-mediated gene transfer of antisense cyclin $\mathrm{G} 1$ (CYCG1) inhibits proliferation of human osteogenic sarcoma cells. Cancer Res. 1995;55(23):5493-5498.

16. Yan J, Jiang JY, Meng XN, Xiu YL, Zong ZH. MiR-23b targets cyclin $G 1$ and suppresses ovarian cancer tumorigenesis and progression. J Exp Clin Cancer Res. 2016;35:31 . doi:10.1186/s13046-0160307-1.

17. Kimura SH, Ikawa M, Ito A, Okabe M, Nojima H. Cyclin G1 is involved in G2/M arrest in response to DNA damage and in growth control after damage recovery. Oncogene. 2001; 20(25):3290-3300.

18. Okamoto $\mathrm{K}$ and Beach $\mathrm{D}$. Cyclin $\mathrm{G}$ is a transcriptional target of the $\mathrm{p} 53$ tumor suppressor protein. EMBO J. 1994; 13(20):4816-4822.

19. Gordon EM, Ravicz JR, Liu S, Chawla SP, Hall FL. Cell cycle checkpoint control: The cyclin G1/Mdm2/p53 axis emerges as a strategic target for broad-spectrum cancer gene therapy - A review of molecular mechanisms for oncologists. Mol Clin Oncol. 2018;9(2):115-134. doi:10.3892/mco.2018.1657.

20. Fernández-Aroca DM, Roche 0 , Sabater S, Pascual-Serra R, Ortega-Muelas M, Sánchez Pérez I, et al. P53 pathway is a major determinant in the radiosensitizing effect of Palbociclib: Implication in cancer therapy. Cancer Lett. 2019;451:23-33. doi:10.1016/j.canlet.2019.02.049.

21. Spiegelberg D, Mortensen AC, Lundsten S, Brown CJ, Lane DP, Nestor M. The MDM2/MDMX-p53 Antagonist PM2 Radiosensitizes Wild-Type p53 Tumors. Cancer Res. 2018;78(17):5084-5093. doi:10.1158/0008-5472.CAN-18-0440.

22. Hou W, Bukong TN, Kodys K, Szabo G. Alcohol facilitates HCV RNA replication via up-regulation of miR-122 expression and inhibition of Cyclin G1 in human hepatoma cells. Alcohol Clin Exp Res. 2013; 37(4):599-608.

23. Xu L, Lin X, Zheng Y, Zhou H. Silencing of heat shock protein 27 increases the radiosensitivity of non-small cell lung carcinoma cells. Mol Med Rep. 2019;20(1):613-621. doi:10.3892/mmr.2019.10263

24. Tian JM, Ran B, Zhang CL, Yan DM, Li XH. Estrogen and progesterone promote breast cancer cell proliferation by inducing cyclin G1 expression. Braz J Med Biol Res. 2018;51(3):1-7. doi:10.1590/1414-431X20175612.

25. Huang CS, Chu J, Zhu XX, Li JH, Huang XT, Cai JP, et al. The C/EBPß-LINC01133 axis promotes cell proliferation in pancreatic ductal adenocarcinoma through upregulation of CCNG1. Cancer Lett. 2018;421:63-72. doi:10.1016/j.canlet.2018.02.020 
26. Yin JJ, Cheng XY. MicroRNA-23a inhibits the growth of papillary thyroid carcinoma via regulating cyclin G1. Eur Rev Med Pharmacol Sci. 2019;23(8):3431-3439. doi:10.26355/eurrev_201904_17707.

27. Giovannini $C$, Minguzzi M, Baglioni M, et al. Suppression of $p 53$ by Notch3 is mediated by Cyclin $\mathrm{G} 1$ and sustained by MDM2 and miR-221 axis in hepatocellular carcinoma. Oncotarget. 2014;5(21):10607-10620. doi:10.18632/oncotarget.2523.

28. Jensen MR, Factor VM, Fantozzi A, Helin K, Huh CG, Thorgeirsson SS. Reduced hepatic tumor incidence in cyclin G1-deficient mice. Hepatology. 2003;37(4):862-870. doi:10.1053/jhep.2003.50137.

29. Yan H, Jiang J, Du A, Gao J, Zhang D, Song L. Genistein Enhances Radiosensitivity of Human Hepatocellular Carcinoma Cells by Inducing G2/M Arrest and Apoptosis. Radiat Res. 2020;193(3):286-300. doi:10.1667/RR15380.1.

30. Kwon SH, Park JC, Ramachandran S, Cha SD, Kwon KY, Park JK, et al. Loss of cyclin g1 expression in human uterine leiomyoma cells induces apoptosis. Reprod Sci. 2008;15(4):400-410. doi:10.1177/1933719107314063.

\section{Figures}




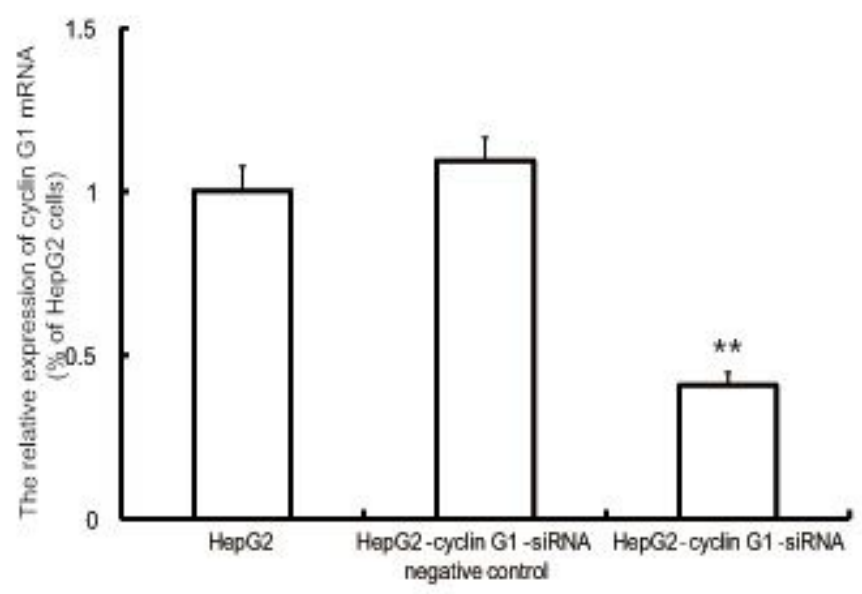

B

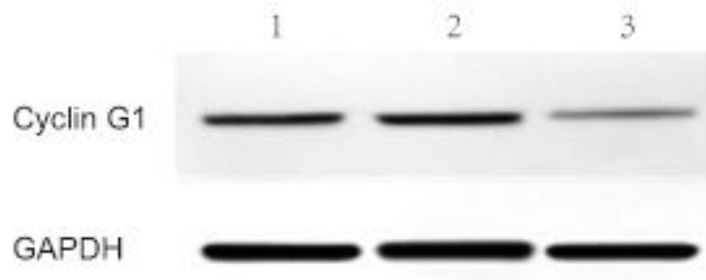

C

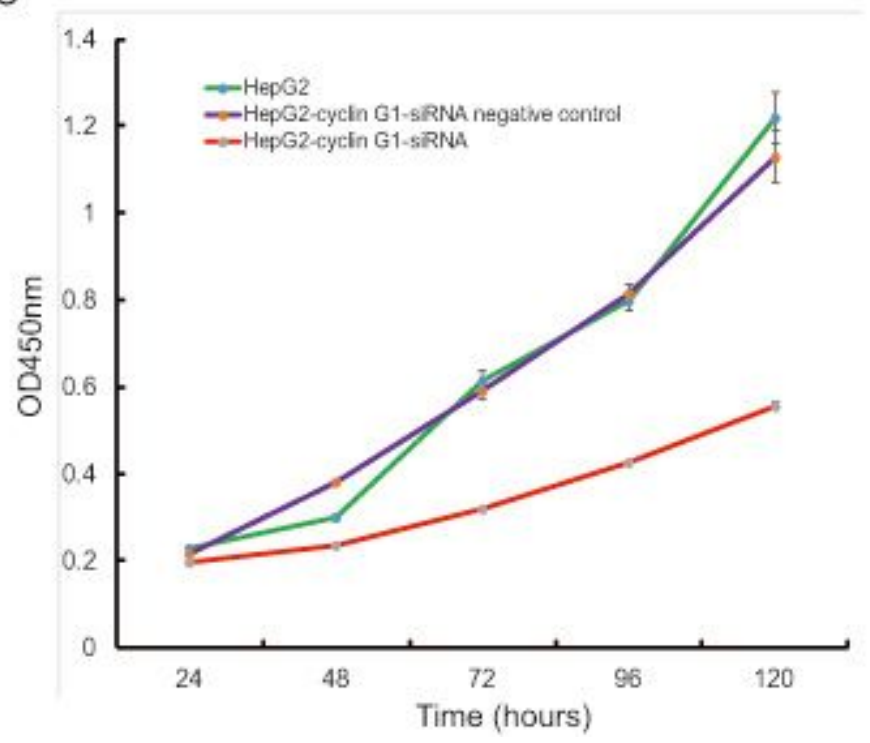

Figure 1

Silencing the expression of cyclin G1 inhibits HCC cell proliferation. (A) Cyclin G1 mRNA in HepG2, HepG2-cyclin G1-siRNA and HepG2-cyclin G1-negative control cells was measured by real time RT-PCR, and normalized to $\beta$-actin. (B) Cyclin G1 protein expression was analysed by western blot analysis in HepG2, HepG2-cyclin G1-siRNA and HepG2-cyclin G1-negative control cells. (C) Silencing the expression of cyclin G1 inhibits the proliferation of HepG2 cells by MTT assay. MTT assay was carried out at 24h, 48h, 72h, 96h and 120h after transfeciton of cyclin G1-siRNA and cyclin G1-siRNA-negative control. Each experiment was performed three times. Data were expressed as the mean \pm S.D. ${ }^{\star} * p<0.01$ vs HepG 2 cells. 


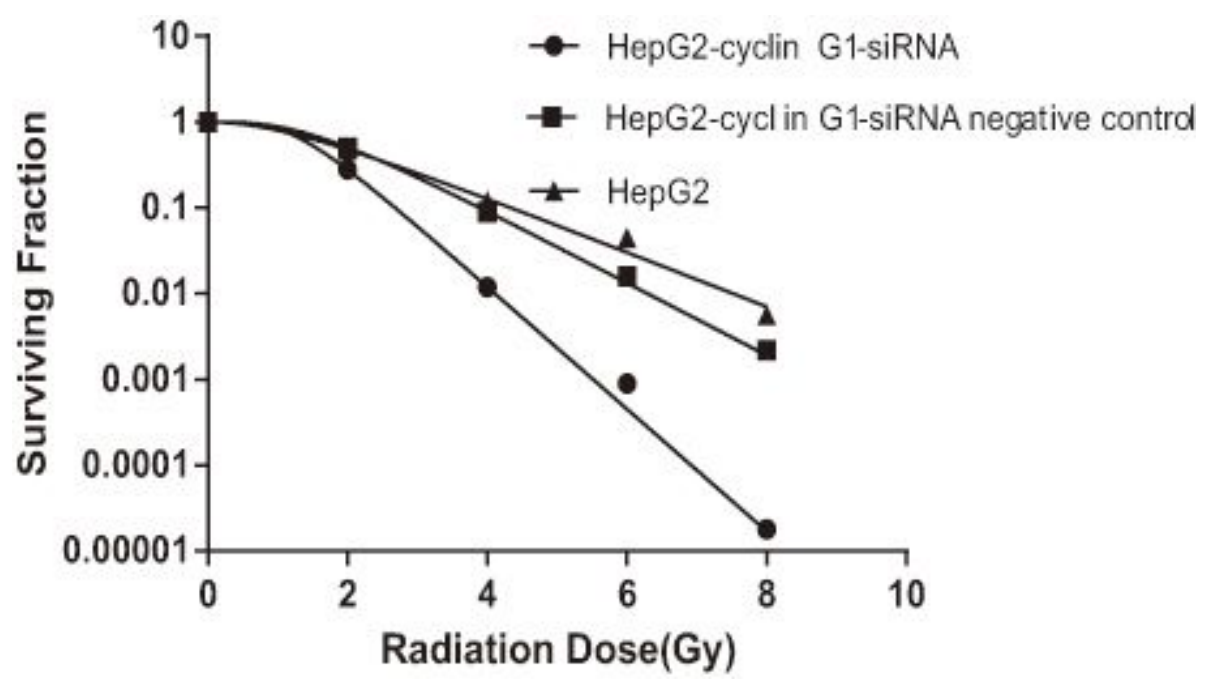

Figure 2

Silencing the expression of cyclin G1 enhances the radiosensitivity of HepG2 cells in vitro. HepG2 cells, HepG2-Cyclin G1-siRNA and HepG2-Cyclin G1-siRNA negative control cells were plated in 6-well plates and irradiated with 0 to $8 \mathrm{~Gy}$ of $6 \mathrm{MVX}$-ray. The cells were cultured for another 14 days, and the number of colonies was counted. Each experiment was performed at least three times. The dose-survival curves were plotted and the values of D0, Dq and SERDq were calculated using GraphPad 5 software. 
A

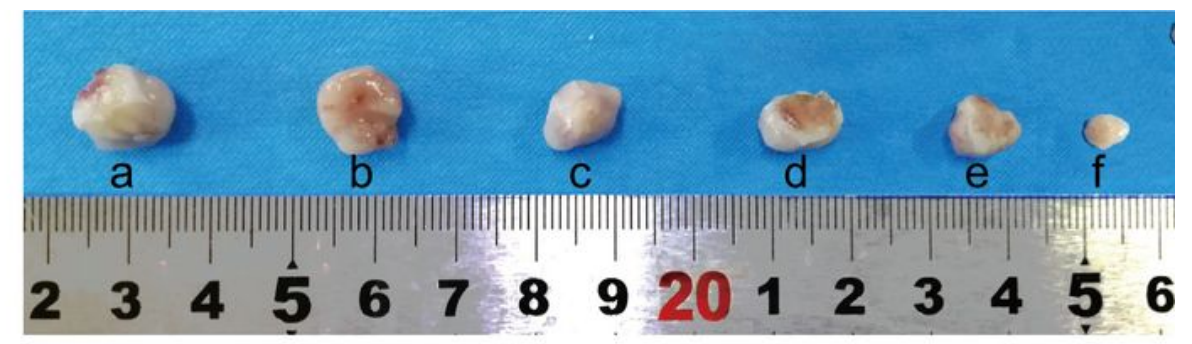

$\mathrm{B}$

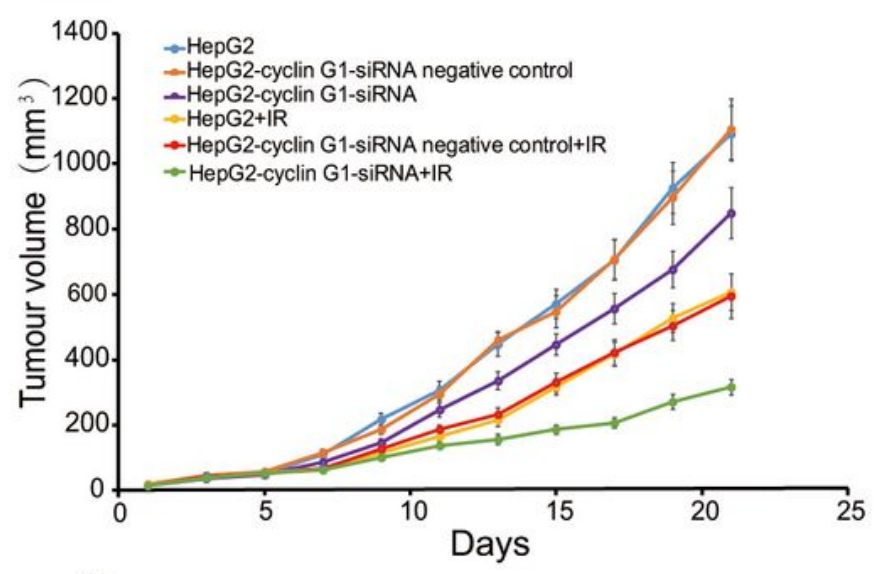

C

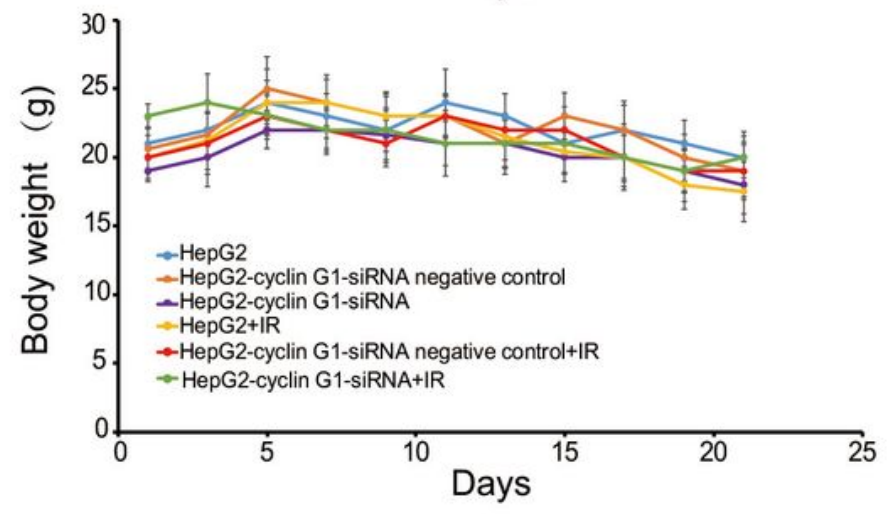

D

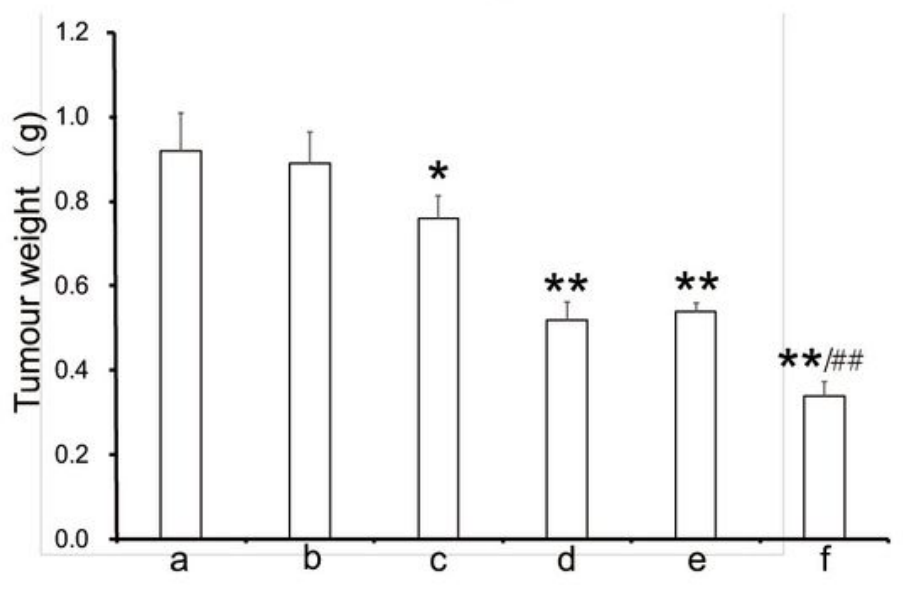

\section{Figure 3}

Silencing the expression of cyclin $\mathrm{G} 1$ enhances the radiosensitivity of HepG2 cells in vivo (A) Representive images of tumours in different groups. (B) Tumour growth curve of tumour volume in a xenograft analysis. Xenograft tumours were treated with $20 \mathrm{~Gy}$ radiation in 5 fractions (4 Gy per fraction, once every 2 days). The volume of tumours was measured every 2 days. (C) Body weight of the Balb/c mice in different groups. (D) Tumor weight in different groups after 21 days. Data were expressed as the 
mean $\pm S . D \llbracket n=5$, ** $p<0.01$ vs HepG2 cells $₫ \# \# p<0.01$ vs HepG2+IR. a, HepG2; b, HepG2-cyclin G1-siRNA negative control; c, HepG2-cyclin G1-siRNA; d, HepG2+IR; e, HepG2-cyclin G1-siRNA negative control+ IR; f, HepG2-cyclin G1-siRNA+IR. IR, irradiation.
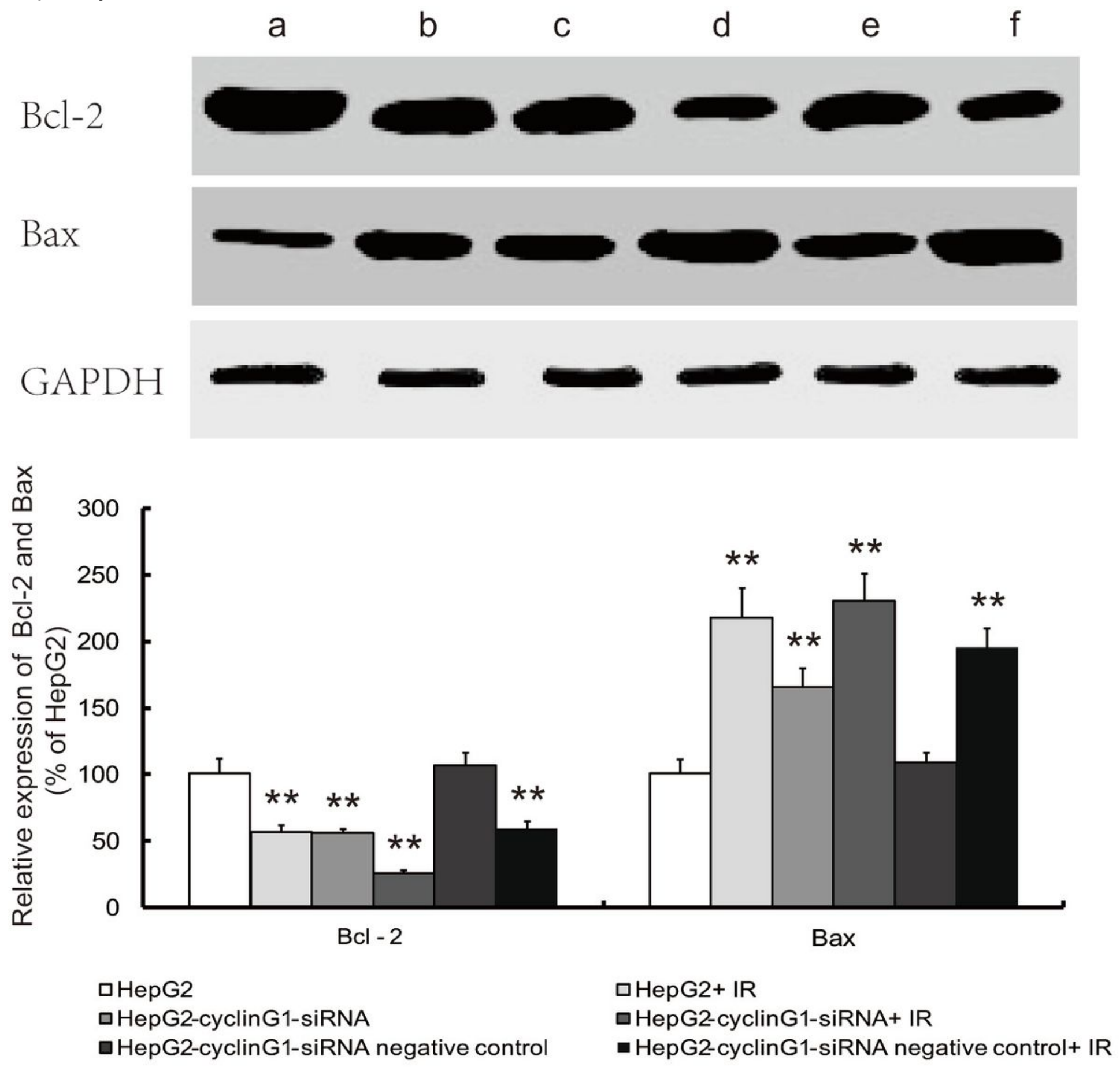

Figure 4

Silencing the expression of Cyclin $\mathrm{G} 1$ decreased the expression of $\mathrm{Bcl}-2$ and increased the expression of Bax. The proteins of Bcl-2 and Bax in HepG2, HepG2-cyclin G1-siRNA and HepG2-cyclin G1-siRNA negative control cells irradiated with 8Gy X-ray were analysed by western blot analysis. a, HepG2; b, HepG2+ IR; c, HepG2-cyclin G1-siRNA; d, HepG2-cyclin G1-siRNA+IR; e, HepG2-cyclin G1-siRNA negative 
control; f, HepG2-cyclin G1-siRNA negative control + IR. IR, irradiation. Each experiment was performed three times, data were expressed as the mean \pm S.D. ${ }^{*} p<0.01$ vs HepG 2 cells. 